\title{
Research-based interventions in the area of proof: the past, the present, and the future
}

\author{
Gabriel J. Stylianides ${ }^{1} \cdot$ Andreas J. Stylianides $^{2}$
}

Published online: 20 September 2017

(C) Springer Science+Business Media B.V. 2017

\begin{abstract}
The concept of proof has attracted considerable research attention over the pastdecades in part due to its indisputable importance to the discipline of mathematics and tostudents' learning of mathematics. Yet, the teaching and learning of proof is an instructionallyarduous territory, with proof being recognized as a hard-to-teach and hard-tolearn concept atall levels of education. Prior research has examined, documented, and cast light on theprocesses underpinning different problems of classroom practice in the area of proof, buthas paid less emphasis on acting upon such problems to generate possible solutions throughresearch-based interventions in mathematics classrooms. In this Editorial, we first situate thecontributions in this Special Issue in a brief chronological account of scholarly work on research-based interventions in the area of proof, and we conclude with a proposal for somehigh-leverage directions for future research.
\end{abstract}

Keywords Proof Interventions $\cdot$ Classroom-based research $\cdot$ Teaching $\cdot$ Learning $\cdot$ Mathematics

In this Editorial, we offer a brief chronological account of scholarly work on research-based interventions in the area of proof. We begin with a consideration of the past in order to situate the Special Issue, which reflects the present state of research in this area. We conclude with a projection into the future by looking ahead 15 or 20 years from now and thinking what we would like intervention-oriented research in the area of proof to accomplish by that time.

\section{The past}

Several researchers have expressed concern that educational research has played a limited role in supporting improvement of classroom practice, especially improvement of students'

Gabriel J. Stylianides

gabriel.stylianides@education.ox.ac.uk

1 Department of Education, University of Oxford, 15 Norham Gardens, Oxford OX2 6PY, UK

2 University of Cambridge, Cambridge, UK 
learning of mathematics (e.g., Cai et al., 2017; Heid et al., 2006; Ruthven \& Goodchild, 2008; Silver, 2003; Wiliam \& Lester, 2008). Students' learning of proof is no exception to this trend (Stylianides, Bieda, \& Morselli, 2016; Stylianides, Stylianides, \& Weber, 2017). A recent review of the state of the art in the area of proof has reached the following conclusions:

(1) there are a good number of well-developed theoretical frameworks casting light on different aspects of the teaching and learning of proof at various levels of education; (2) there is a rather extended knowledge base about how students understand (typically misunderstand) proof; (3) there is a good knowledge base about the current, largely marginal, place of proof in typical school mathematics classroom practice; and (4) there are a relatively small number of research studies that have developed promising classroom-based interventions to address important issues of the teaching and learning of proof. (Stylianides et al., 2017, p. 258)

The first three conclusions in this quotation arguably deserve or approximate the status of "solid findings" of research on mathematics teaching and learning in the area of proof, as the notion of "solid findings" was used by the Education Committee of the European Mathematical Society (2011a, 2011b). ${ }^{1}$ Actually, one of the solid findings identified by the Education Committee of the European Mathematical Society (2011a) relates specifically to the second conclusion in the quotation: many students have the misconception that a few confirming examples suffice to prove the truth of a mathematical generalization. The Education Committee of the European Mathematical Society (2011a) noted the following about the accumulated research evidence concerning this student misconception in the area of proof:

[C]onsiderable evidence exists that many students rely on validation by means of one or several examples to support general statements, that this phenomenon is persistent in the sense that many students continue to do so even after explicit instruction about the nature of mathematical proof, and that the phenomenon is international ... (pp. 50-51)

Indeed, a wealth of mathematics education research thus far has examined, documented, and cast light on different problems of classroom practice in the area of proof, such as the problem described in the previous quotation. Yet less emphasis has been placed on acting upon such problems to generate possible solutions through the design, implementation, and evaluation of research-based interventions in mathematics classrooms (Stylianides et al., 2017). Of course, there are notable examples of research-based interventions in the area of proof (for a review, see Stylianides et al., 2017, pp. 253-258), but the number of these studies is rather small and acutely disproportionate to the number of studies that have supported the first three conclusions in the quotation at the beginning of this section.

\footnotetext{
${ }^{1}$ The Education Committee of the European Mathematical Society (2011b, p. 46) defined "solid findings" as follows:
}

- result from trustworthy, disciplined inquiry, thus being sound and convincing in shedding light on the question(s) they set out to answer.

- are generally recognized as important contributions that have significantly influenced and/or may significantly influence the research field.

- can be applied to circumstances and/or domains beyond those involved in this particular research.

- can be summarized in a brief and comprehensible way to an interested but critical audience of nonspecialists (especially mathematicians and mathematics teachers). 
This Special Issue is a step towards addressing this research gap and, what we anticipate, a trigger for an upsurge in intervention-oriented research in the area of proof so that in 15 or 20 years from now the accumulated knowledge from this body of research will transform the fourth conclusion in the quotation from a problem (as we classify it today due to the small number of available promising interventions) into a set of new solid findings. But before we consider the future of intervention-oriented research in the area of proof, we discuss briefly the present state of this research as reflected in the papers published in this Special Issue.

\section{The present}

At the core of all seven contributions in this Special Issue is the fundamental mathematical concept of proof whose meaning has been the subject of different perspectives in the mathematics education literature (for a summary of some of these perspectives, see: Balacheff, 2002; Stylianides et al., 2017; Weber, 2008). Although in this Editorial we use the term "proof" in line with the conceptualization elaborated in Stylianides (2007) to broadly mean a mathematical argument for or against a mathematical claim that is both mathematically sound and conceptually accessible to the members of the local community where the argument was offered, we recognize there are several viable perspectives to the meaning of proof that can serve different purposes in mathematics education research. ${ }^{2}$ Indeed, our main expectation of authors in this Special Issue with regard to their perspective on the meaning of proof (or related concepts, such as proving and argumentation) was clarity about their own perspective so as to facilitate the readers' understanding of the claims and findings reported in the papers.

Irrespective of one's perspective on the meaning of proof, the point stands that proof is important not only to the discipline of mathematics but also to students' learning of mathematics. This, together with the broad recognition of proof as a hard-to-teach and hard-to-learn concept at all levels of education, have been the main reasons for which we felt that intervention-oriented research in the area of proof deserved to be the focus of a Special Issue in Educational Studies in Mathematics. This particular kind of research is timely because, as we noted earlier, prior research in this area has enhanced the field's understanding of different kinds of learning obstacles that students encounter while engaging with the concept of proof and thus has provided a strong empirical and theoretical foundation that can be utilized in the design of classroom-based interventions to tackle some of these obstacles. In this Special Issue, we use the term intervention to denote action taken to improve a situation in relation to the teaching and learning of mathematics (in our case, in the area of proof), and the term classroom to broadly denote a formal learning setting at any level of education (Stylianides \& Stylianides, 2013, p. 334).

We had two related aims for putting together this Special Issue. The first aim was to offer a collection of studies on empirically-tested and theory-based interventions that either held promise for addressing some key problems of students' learning in the area of proof or offered useful insights for further research, including why certain apparently promising approaches might not yield the desired student learning outcomes. Our openness to interventions with varying degrees of success is based on the recognition that research on the design of

\footnotetext{
${ }^{2}$ We also define broadly the related concept of proving to denote the mathematical activity associated with the search for a proof (Stylianides, 2007). Proving can involve a multiplicity of processes or auxiliary activities, such as working with examples to generate conjectures or develop an insight into the development of a proof (e.g., Lockwood, Ellis, Dogan, Williams, \& Knuth, 2012), or using rhetorical means to convince others that a statement is true or false (e.g., Boero, Garuti, \& Mariotti, 1996).
} 
interventions that aim to navigate pedagogically arduous territories can benefit not only from recounting success stories (which are scant anyway) but also from critical reflection on cases where the expected potential of success was not ultimately fulfilled. The latter can inform the further development of interventions thus increasing the likelihood for more positive outcomes in the future. The second aim was to inspire further research on classroom-based interventions in the area of proof thus tilting the balance from documenting problems of students' learning towards seeking ways to address them. Of course, this is not to deny the relationship between the processes of documenting and addressing problems of students' learning. Indeed, a premise underlying our own research on classroom-based interventions (e.g., Stylianides \& Stylianides, 2009, 2014) has been that, by engineering ways to address problems of classroom practice, one develops also a better theoretical understanding of the nature of these problems and their various dimensions (didactical, mathematical, epistemological, etc.).

In seeking papers for the Special Issue, we made an open call for paper proposals to attract the best and up to date research in the field on classroom-based interventions in the area of proof. We received over 35 submissions responding to the call, the majority of which were of high quality and generally in line with the scope of the Special Issue, thus making it difficult for us to decide which contributions to invite for the next step in the process. The selection was guided by the following three criteria: (1) the degree of fit of the reported research with the theme of the Special Issue, (2) the quality of the reported research and its potential for an important contribution to intervention-oriented research in the area of proof, and (3) our interest to curate a Special Issue representative of different aspects of this kind of research and from a variety of perspectives and international scholars.

Application of these criteria led to extending an invitation to authors of ten paper proposals to develop them into full papers. Before being subjected to the standard review process for publication in Educational Studies in Mathematics, the papers went through an internal review and revision process based on input from us and other potential contributors to the Special Issue. In the end, seven papers were accepted for publication and are included in this Special Issue. These seven papers, together with the invited commentary on the papers by Elena Nardi and Eric Knuth, include contributors from nine different countries: China, Colombia, Israel, Italy, Portugal, Japan, Spain, the UK, and the USA. The seven papers report research that spans various levels of education (secondary school mathematics and university mathematics including teacher education), mathematical domains (arithmetic, algebra, geometry, trigonometry, real analysis, and number theory), and learning environments (paper-and-pencil and others supported by dynamic geometry software or multimedia resources), and, as a collection, they make complementary contributions to intervention-oriented research in the area of proof.

Five papers report on interventions that held promise for enhancing secondary students' learning of proof. The first three of these papers dealt with students' abilities to use examples or diagrams to investigate whether a statement is true or a proof is valid (Komatsu), to progress from empirical to deductive arguments through a dialectic between conjecturing and proving (Fiallo \& Gutiérrez), or to generalize and justify mathematical assertions (Mata-Pereira \& da Ponte). The careful design of mathematics tasks and the purposeful role of the teacher in managing students' proving activity featured prominently in these interventions and are key factors in the authors' explanatory accounts of the promising outcomes obtained from the implementation of the interventions. The fourth paper reports on an intervention that held promise for enhancing (indirectly) undergraduate students' learning of proof, by introducing changes to the way in which a university lecturer presents a specific proof to students (Gabel \& Dreyfus). Central to this intervention was a framework for analyzing different elements of 
proof presentation and the likely impact of strategic changes to these elements on students' proof comprehension. The fifth paper reports on an intervention that held promise for enhancing prospective teachers' knowledge of culturally rooted ways of thinking related to proof in the context of elementary arithmetic theorems (Guala \& Boero). Underpinning the design of this intervention was a framework for a cultural (epistemological, historical, and anthropological) analysis of the content and the introduction of a rationality tool for use by the participants to perform such an analysis.

The kind of empirical evidence that was offered in support of the promise of these interventions varied considerably across the five papers; the evidence was contextualized in different research designs and was underpinned by different theoretical frameworks, including different perspectives on the meaning of proof. Thus, we may talk about qualitatively different kinds of "promise" of the interventions promoting the respective aspects of students' learning of proof. Yet the papers not only showed that the interventions "work" (or "can work") but also, and most importantly, tried to explain how things "worked," thus casting light on the mechanisms of success. As we discussed elsewhere (Stylianides \& Stylianides, 2013, in press), theorizing the mechanisms of success by offering a rational, evidence-based account of how the outcomes of an intervention related to design principles is necessary for ruling out the possibility that the impact of the intervention was due to idiosyncratic factors, such as a fortunate coincidence of particular teacher, student, and classroom characteristics. All five papers make this case and offer to readers a basis on which to decide which components of the interventions are theoretically essential when considering how to adapt the interventions for use in new contexts.

The last two papers in the Special Issue report on interventions whose expected potential for enhancing students' learning of proof was not ultimately fulfilled. One of the interventions aimed to help secondary students improve their ability in constructing auxiliary lines for solving proving tasks in geometry (Fan, Qi, Liu, Wang, \& Lin), while the other aimed to help undergraduate students comprehend proofs (Roy, Inglis, \& Alcock). Both interventions had a well-developed and research-informed pedagogical basis that allowed justifiable optimism for positive outcomes: the intervention by Fan and colleagues inducted students into the use of geometrical transformations in drawing auxiliary lines for solving proving tasks in geometry, while the intervention by Roy and colleagues used multimedia resources that presented proofs with audio commentary and visual animations designed to focus students' attention on logical relationships during proof comprehension. In each case, the efficacy of the intervention was examined in the context of an experimental or a quasi-experimental research design. Although in both cases the experimental groups did not outperform the control groups, as had been hypothesized, critical reflection on the results, including further empirical examination, offered useful insights for further research. In particular, Fan et al. suggested, on the basis of qualitative analysis of students' scripts, that an intervention using a transformation approach to the teaching of auxiliary lines might have a more notable impact on students' engagement with high-level (cognitively demanding) proving tasks than with simpler proving tasks. Roy et al. suggested, on the basis of a follow-up experiment, that the way in which proofs are presented using multimedia resources might interfere with students' ability to integrate new understandings with existing knowledge. Similar to the previous set of papers, the last two papers offer an empirically and theoretically grounded way in which the results from the two interventions can be interpreted.

We will not say more about the seven papers as the commentary by Nardi and Knuth at the end of the Special Issue provides an in-depth discussion of the papers and identifies themes 
that emerge from the entire collection. We turn now to consider in a forward-looking way intervention-oriented research in the area of proof.

\section{The future}

We will look ahead 15 or 20 years from now and think what we would like research on classroom-based interventions in the area of proof to accomplish by that time. At a general level, we hope that the research knowledge that will be accumulated will generate "solid findings" about ways in which instruction can enhance students' learning of proof, as we explained in section 1 . How can we reach that point?

Clearly, we need more intervention studies in the area of proof but, as a field, we have limited resources. Also, the concept of proof is not the only one of importance to students' learning of mathematics. For example, Schoenfeld (2009, p. xii) who described proof as the "soul" of mathematics also characterized problem solving as the "heart" of mathematics. Indeed, similar to proof, problem solving is an important concept that students of all levels of education find difficult and thus also merits attention by intervention-oriented research. These pragmatic considerations (related to limited resources) make us argue that the field should identify priorities for intervention-oriented research in the area of proof so as to address more strategically the many open questions that currently exist in this research domain. In what follows we put forward, for consideration by the field, proposals for two high-leverage research directions.

The first research direction concerns the design of classroom-based interventions in the area of proof at the elementary school level. Symptomatic of the status of research on the teaching and learning of proof, where the focus has been on the upper levels of education (Stylianides et al., 2016, 2017), this Special Issue has no contributions that look into proof in elementary mathematics. We see at least three related advantages from having more intervention-oriented research focusing on the elementary school level. From a curricular standpoint, this research can help with the realization of calls, expressed by curriculum frameworks in several countries and supported by many researchers and educators, for an increased attention to proof in all students' mathematical experiences and as early as the elementary school (see, e.g., the US Common Core State Standards for School Mathematics (CCSSI, 2010) and the English National Mathematics Curriculum (Department for Education, 2013)). From an epistemological standpoint, this research can help achieve more continuity in students' ways of thinking about mathematics across different levels of education by decreasing the gap that exists currently in many countries between elementary and secondary school mathematics with students' abrupt introduction to proof in the secondary school (e.g., Ball, Hoyles, Jahnke, \& Movshovitz-Hadar, 2002). From a pedagogical standpoint, the problems of post-elementary students' learning of proof might become less serious and less resistant to remediation than they are currently if more attention was paid to helping students overcome some hurdles in their engagement with proof in the elementary school (Stylianides, 2016).

The second research direction concerns the design of classroom-based interventions focusing on key and persistent problems of students' learning in the area of proof. By "key," we refer to problems that are important from a disciplinary perspective and have an adverse effect on students' future learning of proof. By "persistent," we refer to problems that have been found to be widespread among students and resistant to remediation. The student misconception that we described in section 1, and which the Education Committee of the European Mathematical Society (2011a) has identified as a solid finding of mathematics education research, fits squarely our definition of a key and persistent problem of students' learning. From a disciplinary 
perspective, the idea that a few confirming examples suffice to prove the truth of a mathematical generalization is in sharp contrast with the conventional meaning of proof as an argument that establishes the truth of a generalization for all possible cases in its domain. From the point of view of students' future learning of proof, if elementary students are led "to believe that a few well-chosen examples constitute proof, it is natural to expect that the idea of proof in high school geometry and other [mathematics] courses will be difficult for the students" (Martin \& Harel, 1989, pp. 41-42). Regarding the issue of persistence, the Education Committee of the European Mathematical Society (2011a) noted that the misconception is held by many students and in many countries (i.e., the problem is widespread) and that many students continue to hold the misconception even after explicit instruction about the nature of proof (i.e., the problem is also resistant to remediation). Other problems that meet our definition of key and persistent problems of students' learning in the area of proof include the misconception that a single counterexample is insufficient to refute a false mathematical generalization (e.g., Mason \& Klymchuk, 2009; Simon \& Blume, 1996) or the misconception that a conditional statement is equivalent to its converse (e.g., Hoyles \& Küchemann, 2002; Yu, Chin, \& Lin, 2004). In Stylianides and Stylianides (in press) we discuss three characteristics that we consider important for researchers to take into account as they design classroom-based interventions to address key and persistent problems of students' learning in the area of proof: (1) the interventions have an explanatory theoretical framework about how they "work" or "can work" in relation to their impact on students' learning; (2) they have a narrow and well-defined scope, which makes it possible for them to have a relatively short duration; and (3) they have an appropriate mechanism to trigger and support conceptual change.

As the number of classroom-based interventions in the area of proof continues to grow, the field ought to consider how these interventions relate to each other and how they can fit together in an overall instructional program aiming to support students' learning of proof alongside their learning of other mathematical concepts. In order to tackle these questions, we need to pay close attention to what might constitute the unit of an intervention in such an instructional program. What can be a single and complete intervention that can help address specific learning goals and form an individual component (building block) of a larger instructional program in the area of proof? We argue for a unit that is as small as it is realistically possible, with each individual intervention targeting a well-defined and possibly modest set of learning goals, such as to help students overcome one of the misconceptions we mentioned in the previous paragraph. A unit of this kind would allow a rather flexible use of interventions in the composition of a larger instructional program (Stylianides \& Stylianides, in press). Furthermore, a unit of this kind would likely be associated with interventions of a short duration, which arguably can be more easily incorporated into existing curricular structures and used at scale (Stylianides \& Stylianides, 2013). Given that intervention-oriented research in the area of proof is still at its early stages, it is a strategic time for researchers to consider the issue of the unit of an intervention and to factor this consideration into the design of new interventions.

\section{Concluding remarks}

We hope that readers will find the contributions in this Special Issue inspirational for further research on classroom-based interventions in the area of proof but also in other areas of mathematics education where similar issues exist. Prior research has extensively documented numerous problems of students' learning in the area of proof and beyond. The time has come 
for research to place more emphasis on seeking solutions to these problems, thereby promising a better future for students' learning of mathematics at all levels. Undoubtedly, this will be a long and arduous road. Thus, as we have argued in this Editorial, it is strategic for the field to identify a small number of high-leverage directions for future research. It is also strategic for the field to reflect on what might constitute the building blocks (units) of a future, comprehensive instructional program in the area of proof, and organize the design of individual interventions according to a broad, coherent, and forward-looking plan.

Acknowledgements We contributed equally both to the preparation of this Editorial and to the preparation of this Special Issue as Guest Editors. We wish to thank Vilma Mesa for her helpful comments on an earlier version of the Editorial.

\section{References}

Balacheff, N. (2002). The researcher epistemology: A deadlock for educational research on proof. In F. L. Lin (Ed.), Proceedings of the 2002 international conference on mathematics: Understanding proving and proving to understand (pp. 23-44). Taipei: NSC and NTNU. Pre-publication version retrieved November 25, 2011, from http://www.tpp.umassd.edu/proofcolloquium07/reading/Balachef_Taiwan2002.pdf

Ball, D. L., Hoyles, C., Jahnke, H. N., \& Movshovitz-Hadar, N. (2002). The teaching of proof. In L. I. Tatsien (Ed.), Proceedings of the international congress of mathematicians (Vol. III, pp. 907-920). Beijing: Higher Education Press.

Boero, P., Garuti, R., \& Mariotti, M. A. (1996). Some dynamic mental processes underlying producing and proving conjectures. Proceedings of the 20th Conference of the International Group for the Psychology of Mathematics Education (Vol. 2, pp. 121-128). Valencia, Spain: Valencia University.

Cai, J., Morris, A., Hwang, S., Hohensee, C., Robison, V., \& Hiebert, J. (2017). Improving the impact of educational research. Journal for Research in Mathematics Education, 48(1), 2-6.

Common Core State Standards Initiative (CCSSI). (2010). Common core state standards for mathematics. Washington, DC: National Governors Association Center for Best Practices and the Council of Chief State School Officers.

Department for Education. (2013). Mathematics: Programmes of study: Key Stages 1-2 (National Curriculum in England). Retrieved October 31, 2013, from https:/www.gov.uk/government/uploads/system/uploads/attachment_ data/file/239129/PRIMARY national curriculum - Mathematics.pdf.

Education Committee of the European Mathematical Society. (2011a). Do theorems admit exceptions? Solid findings in mathematics education on empirical proof schemes. EMS Newsletter, 82, 50-53.

Education Committee of the European Mathematical Society. (2011b). "Solid findings" in mathematics education. EMS Newsletter, 81, 46-48.

Heid, M. K., Larson, M., Fey, J. T., Strutchens, M. E., Middleton, J. A., Gutstein, E., .. Tunis, H. (2006). The challenge of linking research and practice. Journal for Research in Mathematics Education, 37(2), 76-86.

Hoyles, C., \& Küchemann, D. (2002). Students' understanding of logical implication. Educational Studies in Mathematics, 51, 193-223.

Lockwood, E., Ellis, A. B., Dogan, M. F., Williams, C., \& Knuth, E. (2012). A framework for mathematicians' examplerelated activity when exploring and proving mathematical conjectures. In L. R. Van Zoest, J. J. Lo, \& J. L. Kratky (Eds.), Proceedings of the 34th annual meeting of the North American Chapter of the International Group for the Psychology of Mathematics Education (pp. 151-158). Kalamazoo, MI: Western Michigan University.

Martin, W. G., \& Harel, G. (1989). Proof frames of preservice elementary teachers. Journal for Research in Mathematics Education, 20(1), 41-51.

Mason, J., \& Klymchuk, S. (2009). Using counter-examples in calculus. London: Imperial College Press.

Ruthven, K., \& Goodchild, S. (2008). Linking researching and teaching: Towards synergy of scholarly and craft knowledge. In L. D. English (Ed.), Handbook of international research in mathematics education (2nd ed., pp. 561-588). New York, NY: Routledge.

Schoenfeld, A. H. (2009). The soul of mathematics. In D. A. Stylianou, M. L. Blanton, \& E. J. Knuth (Eds.), Teaching and learning proof across the grades: A K-16 perspective (pp. xii-xvi). New York, NY: Routledge.

Silver, E. A. (2003). Border crossing: Relating research and practice in mathematics education. Journal for Research in Mathematics Education, 34(3), 182-184. 
Simon, M. A., \& Blume, G. W. (1996). Justification in the mathematics classroom: A study of prospective elementary teachers. Journal of Mathematical Behavior, 15, 3-31.

Stylianides, A. J. (2007). Proof and proving in school mathematics. Journal for Research in Mathematics Education, 38, 289-321.

Stylianides, A. J. (2016). Proving in the elementary mathematics classroom. Oxford: Oxford University Press.

Stylianides, A. J., Bieda, K. N., \& Morselli, F. (2016). Proof and argumentation in mathematics education research. In A. Gutiérrez, G. C. Leder, \& P. Boero (Eds.), The second handbook of research on the psychology of mathematics education (pp. 315-351). Rotterdam: Sense Publishers.

Stylianides, A. J., \& Stylianides, G. J. (2013). Seeking research-grounded solutions to problems of practice: Classroom-based interventions in mathematics education. ZDM - The International Journal on Mathematics Education, 45(3), 333-341.

Stylianides, A. J., \& Stylianides, G. J. (2014). Impacting positively on students' mathematical problem solving beliefs: An instructional intervention of short duration. The Journal of Mathematical Behavior, 33, 8-29.

Stylianides, A. J., \& Stylianides, G. J. (in press). Addressing key and persistent problems of students' learning: The case of proof. In A. J. Stylianides \& G. Harel (Eds.), Advances in mathematics education research on proof and proving: An international perspective. Springer.

Stylianides, G. J., \& Stylianides, A. J. (2009). Facilitating the transition from empirical arguments to proof. Journal for Research in Mathematics Education, 40, 314-352.

Stylianides, G. J., Stylianides, A. J., \& Weber, K. (2017). Research on the teaching and learning of proof: Taking stock and moving forward. In J. Cai (Ed.), Compendium for research in mathematics education (pp. 237266). Reston, VA: National Council of Teachers of Mathematics.

Weber, K. (2008). How mathematicians determine if an argument is a valid proof. Journal for Research in Mathematics Education, 39(4), 431-459.

Wiliam, D., \& Lester, F. K. (2008). On the purpose of mathematics education research: Making productive contributions to policy and practice. In L. D. English (Ed.), Handbook of international research in mathematics education (Second ed.pp. 32-48). New York, NY: Routledge.

Yu, J. Y. W., Chin, E. T., \& Lin, C. J. (2004). Taiwanese junior high school students' understanding about the validity of conditional statements. International Journal of Science and Mathematics Education, 2, 257-285. 